\title{
EXPERIENTIAL GROUPS IN THE TRAINING OF GROUP COUNSELORS AND THERAPISTS: A VIEW FROM TRAINEES PERSPECTIVE
}

\author{
Birutè Jakubkaitè, Rimantas A. Kočiūnas \\ Vilnius University, Lithuania \\ E-mail: birutej@gmail.com,rimask@parkas.It
}

\begin{abstract}
Many theorists and practitioners believe that integration of theoretical knowledge, observation of proficient group counselor work, supervision of personal work with groups and personal experience as a group member help future group therapists to acquire skills necessary for group counseling. Personal experience can be acquired through participation in experiential groups. As it is little known of the personal experience of experiential group members, it is not sufficiently clear whether insights and opinions of these members are consistent with those emphasized in the literature about experiential groups in the training context. The aim of this research is to provide a structured description of experiences of experiential group participants in the training context: how trainees perceive experiential groups in the training context. To achieve this aim, a qualitative study strategy was employed which is particularly appropriate in cases when a research object has been little explored and results of available studies are controversial. The research was organized and carried out on the basis of the principles and requirements of thematic analysis. Students from one and the same Group Therapy training program of the Institute of Humanistic and Existential Psychology (Bir tonas, Lithuania) were chosen for this research. In addition to theoretical lectures, program participants went through three experiential groups that were led by experienced group counselors. The work of the group was observed by two program supervisors. Participants of the research were 8 persons aged from 29 to 48. Semi-structured interviews were used to gather research data. The participants were asked to share their experiences, mostly focusing on experiential groups. The analysis of the gathered data crystallized around 5 themes: preliminary expectations; goals of the experiential group; weakness and unsafety of the experiential group; experiential group process continuity; and experiential group as a tool for giving meaning to knowledge and personal transformations. The analysis of research findings revealed that the purpose of experiential groups in training, which is attached most attention in professional literature, i.e. giving meaning to knowledge and facilitation of personal changes, represents only one component in the perceptions of this group. A relationship between the experiential group participants and the group which determines the perception of the group also encompasses preliminary expectations of the participants, their concerns about the goals of the group, realization of weakness and unsafety of the group, and experience of the group process continuity. The analysis of findings paid attention to the importance of identification and definition of group goals. The participants of the group had ambiguous and vague understanding of the group goals, where the group itself was perceived as lacking coherence and commonness. In addition, the analysis of research findings also revealed that differences among group participants impede the formation of the feeling of commonness. This should encourage both researchers and practitioners to pay
\end{abstract}


attention to the selection of participants to experiential groups and programs.

Key words: counselor in training, experiential group, group counselors, group therapists.

\section{Introduction}

Good individual counseling or psychotherapeutic skills are not sufficient for successful and efficient work of group therapists or counselors. Therapeutic groups encounter not only individual dynamics of each participant but also the dynamics of interpersonal relations and the development of the group as a whole (Corey, 2004; Markus \& King, 2003; Yalom \& Leszcz, 2005). Many theorists and practitioners are of the opinion that integration of theoretical knowledge, observation of proficient group counselor work, supervision of personal work with groups and personal experience as a group member help future group therapists acquire the skills necessary for group counseling (Corey, 2004; Brabender, Smolar \& Fallon, 2004; DeLucia, Bowman \& Bowman, 1989; Gladding, 2008; Yalom \& Leszcz, 2005). Experiential groups serve for the acquisition of personal experiences. Participation in the aforementioned groups is included into the requirements of such organizations for the accreditation of group therapists and counselors as the Council for Accreditation of Counseling and Related Education Programs Training Standards or the Association for Specialist in Group Work, as well as into the requirements of most of the master's and doctoral degree programs in psychology (by Shumaker, Ortiz \& Brenninkmeyer, 2011). Experiential groups are also held for future group therapists and counselors in Lithuania (e.g., training of group counselors at the Institute of Humanistic and Existential Psychology or a joint program for group analysis of the Lithuanian Group Analytic Society and Vilnius University). Despite increasing popularity, group therapists' training programs lack a sufficiently clear and consistent scientific evidence of what is going on in experiential groups (Shumaker, Ortiz \& Brenninkmeyer, 2011; Anderson \& Price, 2001; Merta, Wolfgang \& MacNeil, 1993). There is insufficient knowledge of experiences of the group participants (Lennie, 2007; Payne, 1999; Stockton, Morran \& Krieger, 2004). This paper describes a research which constitutes a part of a broader research into experiential groups in the context of training (Jakubkaite \& Kočiūnas, 2013). It focuses on the experiences of the participants of experiential groups in training.

\section{Background of the Problem}

A successful training program has to enable a trainee to gain knowledge how a group process is related to the results of group work and how a group counselor can affect this process and its dynamics (Yalom \& Leszcz, 2005). Experience as a group member is said to be beneficial for future group therapists due to skills development and enhancement of empathy for group participants (Brabender, Smolar \& Fallon, 2004; Corey, 2004; Yalom \& Leszcz, 2005). However, consistent and thorough research studies providing scientific evidence for these statements appear to be lacking nonetheless (Johns, 2012; Lennie, 2007). Although it is argued that personal involvement in experiential groups helps in giving meaning to gain theoretical knowledge on a personal and emotional level of the participants, there are no clear guidelines and recommendations as to what should be happening in these groups and how the groups should be led in fact (Yalom \& Leszcz, 2005). Usually the general meaning of experiential groups for group therapists' training is addressed, whereas specific goals of experiential groups remain not clearly defined: what roles participants should play within the group, what guidelines should they follow, how to form and organize experiential groups, how they are influenced by the specific training context (Johns, 2012; Rose, 2008). Therefore, experiential groups may be overestimated in the training context due to their prevalence in training programs and the lack of empirical studies (Lennie, 2007).

It is noted that the benefits of an experiential group for its members are greater if the group not only develops professional competences, but also provides personal benefits by enhancing personality growth and improving communication skills (Corey, 2004; Kline, 2003). From this point of view experiential groups are similar to human relations groups, T-groups, sensitivity groups, marathon groups, human potential groups, sensory awareness groups, and encounter groups (Yalom \& Leszcz, 2005). All these groups, including experiential groups, focus on the here-and- 
now principle, encourage direct interpersonal interactions, emotional expression, self-disclosure and confrontation that are necessary for first-hand self-analysis and analysis of own behavior in the group, revealing new behavioral opportunities and deeper knowledge of self, learning selfanalysis and group analytical skills (Yalom \& Leszcz, 2005). However, encouraging the openness and disclosure of group participants (who are future group therapists) poses a number of questions relating to dual relationship, confidentiality, privacy and negative experiences of group participants (Anderson \& Price, 2001; Davenport, 2004). Participants' interactions are usually not limited to intragroup interactions. Therefore, it is more difficult to maintain confidentiality in experiential groups, whereas the feeling of safety in the group, which is determined by a clear contract of group work, sharing, mutual trust, knowing each other, commonness of group goals, stability of the group composition and the external environment of the group, is closely related to experiential group satisfaction by the participants (Payne, 2001; Robson \& Robson, 2008).

As it is little known of the personal experiences of the members of experiential groups, it is not sufficiently clear whether insights and opinions of these members are consistent with the benefits of experiential groups emphasized in the literature (Ieva et al., 2009; Payne, 1999; Payne, 2001). Experiential groups should be researched more actively and in more detail in order to better identify the goals of these groups, processes ongoing within the groups and results achieved (Johns, 2012; Payne, 1999). This would help to identify how and to what extent these groups are beneficial for future group therapists. Without knowing the opinion of group participants on the experiences provided by the groups it is impossible to decide how the groups should be organized and led so that to achieve the goals set. It is namely qualitative research methods that can produce an in-depth concept of the experience gained in experiential groups (Payne, 2001).

The aim of this research is to provide a structured description of experiences of experiential groups in the training context, i.e., how the groups are perceived by trainees. To achieve this aim, a qualitative study strategy was used as being highly appropriate in cases when a research object has been extremely little explored, results of available studies are controversial, there is insufficient knowledge of the area at issue and this makes it impossible to formulate clear hypotheses (Barker, Pistrang \& Elliot, 2002).

\section{The Researcher's Role}

In carrying out the qualitative research the authors' role in gathering and analyzing the results is very important. The authors of the research are well aware of the tradition and practice of qualitative research methods and have knowledge of interview-based qualitative research methods and data collection. In addition, the authors have experience in psychological and psychotherapeutic group counseling which helps to understand processes within groups, requirements raised to group counselors and participants' behaviors in groups, as well as are familiar with research trends in the area of experiential groups. The authors' experience and knowledge inevitably influence the organization of the research, choice of questions and goals, and initial assumptions. They are all formulated on authors' attitudes that: (a) group experience is valuable; (b) taking part in experiential training groups helps mastering theoretical knowledge and gaining important skills for group counseling; (c) in the context of training, taking part in the experiential groups training can be most helpful in experiencing the diversity of group dynamics and relationship; (d) taking part in these groups is an intense personal experience. Hence, while gathering and analyzing data much attention has been paid to reflect these attitudes and their likely influence on the perception of results.

\section{Methodology of Research}

\section{General Background of Research}

The research was organized and carried out in accordance with the principles and requirements of a thematic analysis (Braun \& Clarke, 2006). One of the advantages of this method is flexibility that is associated with the ability to satisfy various theoretical approaches. The thematic analysis 
assists in identifying, analyzing and presenting the themes produced by the data. Also, it is possible to interpret the data obtained (Boyatzis, 1998). Considering the aim of this research, the inductive thematic analysis has been chosen, i.e., themes are closely related to the obtained data. According to these principles, the themes that have crystallized out are not squeezed into a prearranged theoretical framework, but emerge directly from the available data. Due to the small number of the participants, a case study of one specific group has been chosen as a research method.

\section{Participants}

Participants of the research were students from one and the same Group Therapy training program of the Institute of Humanistic and Existential Psychology (Bir tonas, Lithuania). In addition to theoretical lectures, program participants attended three experiential groups that were led by experienced group psychotherapists. The work of the group was observed by two program supervisors. Each experiential group took three days. Group members attended four 90 min. sessions a day. The sessions were followed by 2 hours' discussions of the group work and dynamics. During the discussion, group participants, counselors and supervisors expressed their views to processes within the group. The training program was delivered in the Russian language.

There were 8 participants ( 7 women and 1 man) in the research aged between 29 and 48 (mean age -38 years). 6 participants had a background in psychology, 1 in medical psychiatry and 1 in social work. 2 participants of the group psychotherapy training program had no previous experience in group counseling. Only one trainee did not have any experience of personal participation in encounter or psychotherapy groups. 4 participants were from Russia, 1 from Latvia and 3 from Lithuania.

\section{Data Collection}

Research data were gathered by semi-structured interviews. Research participants were asked to share their experiences, mostly focusing on experiential groups. Questions to research participants were formulated as follows: (a) share your experiences about participation in this program; (b) share your experiences about participation in the experiential groups. During the interviews, participants were also asked some clarifying questions that arose in relation to their narratives in order to reveal the participants' experience and its perception as clearly as possible. The interviews took from 30 minutes to 1 hour and 33 minutes (mean duration - 53 minutes). The interviews were tape-recorded and then rewritten in detail. The participants who came from Russia and Latvia were interviewed in Russian. The interviews were held in the premises of the Institute, in a cozy, isolated room.

\section{Ethical Consideration}

In order to meet ethical requirements, the research was organized and carried out on the basis of the assessment criteria developed by Vilnius University for the issuance of psychological research ethics permits (Kazlauskas, 2012). The research was conducted with consent from the Group Therapy program leader. Before the interview, participants were informed about the purpose and course of the research, participation conditions, and filled in informed consent forms. The participants knew that their participation was of a voluntary nature prior to giving their consent and that their refusal to take part in the research would not have any influence on their further participation in the training program and assessments, and that program lecturers and supervisors would not have any direct access to the interview records. The participants had the possibility to refuse from participation at any point. They were also informed about the fact that interviews would be recorded and on the form and length of interview storage. Each participant sigh an agreement to be tape-recorded and agreed all the information that $\mathrm{s} /$ he has told to be published. The true names of the participants mentioned in the interviews were changed and details likely to assist in identifying the authors of certain extracts were eliminated. In addition, the participants had an 
access to all the information necessary for deciding on the participation in the research and/or for contacting the researchers where appropriate.

\section{Data Analysis}

Interview data were analyzed using a 6-phase guide by Braun and Clarke (2006): (a) transcribing interviews, reading and re-reading, noting down initial ideas and remarks; (b) initial coding of the transcribed data in a systematic fashion; (c) searching for themes when the coded data is collated into potential themes; (d) reviewing themes, checking if the themes work in relation to the systematized data and codes; (e) defining and naming themes; (f) selection of interview extracts best reflecting the themes.

\section{Limitation}

As any other research, this research study has its own limitations. Qualitative research strategy does not allow making generalizations - all the findings obtained are presented only in the context of the described group. Participants represent only one school of group therapy and one and the same training group. This narrows down the results and their interpretation. The inclusion of different training programs and more training groups into such research studies could considerably broaden the perception of experiential group experiences in the training context. Describing the experiences of only one group in the research does not allow a broader generalization of research findings which are dependent on the dynamics of a particular group. Identification of more general characteristics of experiential groups requires research covering possibly more groups of trainees. This would reduce the influence of the dynamics of a particular group on research results and would contribute to a more precise description of experiential groups.

\section{Results of Research}

The data analysis crystallized around 5 themes which, through the relationship between participants and experiential group, reflect how the participants perceive the experiential groups which members they are:

(a) preliminary expectations; (b) goals of the experiential group; (c) weakness and unsafety of the experiential group; (d) experiential group process continuity; and (e) experiential group as a tool for giving meaning to knowledge and personal transformations.

\section{Relationship between Participants \\ and the Experiential Group - Preliminary Expectations}

Referring to their expectations towards the program and groups, all research participants emphasize choosing the program namely for the experiential groups offered by the program. Some participants expect to receive personal help: /.../1 when I was studying ten years ago, in autumn, ... general experiences, therapeutic experiences were in the first place and only then learning /.../ my expectations are therefore therapeutic; others expect to become group therapists: /.../ my primary goal is learning. That's why I'm here. And I will definitely be in this job; some others are interested in acquiring the experience of being a member and getting to know group psychotherapy in practice: /.../ I didn't have experience in group work, so I wanted to see, to feel, as much as possible, what it is /.../ namely to feel what a group is as a whole, how it functions. Behavioral patterns chosen by the participants and their attitude towards the group depend on whether or not their expectations come true: /.../ if something doesn't match my expectations I simply disassociate and don't participate. 


\section{Relationship between Participants and the Experiential Group - Goals of the Experiential Group}

This theme reflects a confusion of the participants of the group arising from a controversial understanding of the goals of the experiential group in the context of training. Participants often ask a question of goal priority: is it the experience as that of a member or the professional understanding of group processes. When first exposed to the experiential group in this training program, participants often perceive those goals as hardly compatible or even conflicting: /.../ it's not very clear for me what I should do /.... For me, "experiential" means tackling personal problems, while "training" means that the groups should be either very small or conditional, and there is a lot of analysis, remembering what's going on /.../ I feel confused all the time and I can't find my place. The role of program counselors and group therapists are also insufficiently clear to the participants in the context of identification of group goals: /.../ therapists say "it's training", but X explains us that we have to bear psychotherapeutic processes in mind /.../ it's not only training but therapy as well /.../So what is it? The participants of the group therapy training program wonder whether the experiential group is intended for demonstrating the methods and skills of group counselor's work or for their personal experience as members: /.../ I think if you demonstrate your method, it is demonstration, even if it's in therapy. Yet, it's not treatment. Confusion about the group goals can be also seen in unclear or unidentified personal goals of the participants. This implies their uncertainness about what they want or what goals they have in the group:/.../ professional motivation was more clearly identified than personal one. The situation about personal goals was more complicated in the group. This is stressful /.../ it is difficult when therapeutic goals are not identified.

\section{Relationship between Participants and the Experiential Group - Weakness and Unsafety of the Experiential Group}

The research participants have doubts whether it is possible to experience and understand in these groups how the group is helpful and in what form, and whether it generates any realistic psychotherapeutic benefits: /.../ I need to understand what's going on, what specific implications it [the group] may have. So far, it's a kind of experience you are gaining as a customer, something is going on, but/.../ effects are more of an individual sort. The participants note that the small number of group members poses a threat that the group will fall apart and the training will have to be postponed. Therefore, they are inclined to see artificial efforts on the part of both the participants and program leaders to maintain the group: /.../ We were told from the very beginning "to take care of each other, because if one or two more persons leave, there'll be no group at all". This was very troubling, and it could be clearly felt in the group that it simply has to be maintained so that we can continue training. The participants see weakness of the group in the lack of commonness and try to explain it by inadequate selection of group members which was identical to admission to the program: /.../ when I decided to join the program, I was sure there'll be selection of members I... and I was strongly disappointed when I saw that some of the members have no experience in group work /.../. The point is that our group is very motley and it's very difficult to adapt here. Participants usually characterize each other as unattractive for interaction, strange, lacking professional experience; they consciously try to accept others whilst being aware that they can't avoid being together in the group: /.../ I would never communicate with some of them in real life /.../ if I want to get any help in the group, I have to interact with others, to disclose myself, behave in a personal and sincere matter.

The participants are not sure whether counselors of the group in training are really minded to help them; others perceive the group members as incapable of independent work and of providing psychotherapeutic assistance to each other within the group due to the lack of experience, knowledge and being at the beginner stage of work with groups: /.../ the group is incapable of independent decision making - it is still weak/.../it looks like you cannot trust other group members. The therapist also reduces his responsibility - he is here not to treat. The participants are worried that, bearing in mind the training context, they can be used for the demonstration of methods: /... you know what matters for me? I want them not to hurt me, to act in a professional manner, well, not to use 
me as a toy /.../. Group therapists are perceived as "learning models": /.../ I think he demonstrates his professional competences /.../ of course, he is counseling the group, but also is putting certain stresses, showing one or another methods so that it would be clearer, more exemplary.

On the one hand, the participants do not dare to disclose their personal experiences and problems being afraid that they will not be provided adequate support within the group in training: /... if you don't manage to refrain and get involved in the process, which is for training purposes, you'll be left alone with your unresolved problems. Or, they feel excluded from the group on the ground of certain personal traits that segregate them from general group experiences and impede integration into it, thus restricting open and spontaneous behavior of the group participants. For example, on the ground of sex: /.../ all around are only girls; it's somehow incorrect to protest or show aggression; or the lack of academic training: /.../ it's something related to academic background, to my learning "not" /.../ I have studied, too, but differently; or different occupation: /.../ and, by the way, there were confrontations like "what are social workers doing here?!". Such shades were also present. On the other hand, there is a feeling of some competing: /.../ I think, some competition is present. It's like who of us will be a better therapist in the future. /.../ a kind of some powers and influences in the group. And not only in it. The participants say they cannot be, or let others think they are, weak in this group: /.../ I don't feel as safe as to be able to settle my problems I'm concerned about and that suit to be addressed in this group. I.../ I can't speak, because I know I can't be weak in this group. I have to fight.

Being aware that they will have to communicate outside the boundaries of the group, participants mentioned during the interviews their inhibited expression of naturally arising feelings and behavioral restrictions within the group: /.../Simply, if I were so open and emotional in the group, I understand it's normal /.../, but do I need it now? Because I won't feel comfortable after that [after the group]; also, a great need for confidentiality which is even more strengthened by the fact that the group is monitored and other group members, therapists and supervisors are met in other life contexts: /.../ after the first workshop, at the very end of it, the last day after therapy, I really toothed him - I wanted cast-iron confidentiality from him. I really needed it. /.../ somehow, it was very important, especially when you have to work in the neighboring workplaces after that /.../.

\section{Relationship between Participants and the Experiential Group- Experiential Group Process Continuity}

The research participants noted that the second group continued the processes started in the first experiential group: /.../ according to what people say, the beginning of the second group is the result of the participation in the first group. Similarly, the participants noted that contemplations about the group extend beyond the time spent in the group (during lectures, in daily life): I.../ these group relations and their analysis are perfectly continued there. Well, maybe not so straightforwardly, but in a certain way the group extends prior to it and after it. /.../ I can see us bunching into groups, it's not by coincidence /.../ and me personally, I analyze it /.../ I can see this continuation and, let's say, I work with it afterwards. The processes that started in one group continue not only in another group, but throughout all workshops: /.../ it was important to feel the turn towards greater openness and confidence from inside /.../ and, on the one hand, this was pre-prepared by the earlier groups. Even group discussions are perceived as qualitatively different group meetings, as one more additional group: /.../ it's as if one more group work technique which impacts on group dynamics. It seems to be one more meeting of the group, but in an alternative form. While supervisors are perceived as actors affecting group work: /.../ I think he intentionally says certain things and remarks, for instance, during supervisions and, sometimes, even during lectures. I mean, it seems to me that he is a bit impacting on the group's dynamics this way /.../ after the feedback from the supervisors, the group started from what they talked about. Hence, the discussions not only contribute to the construction of professionals' attitudes towards the group and processes taking place in it, but also help to understand other participants, their feelings and place in the group. They help to make and develop relations and structure the emotional experience gained: /.../ during summary discussions, I can see where my place was /.../ what I was doing. 
First of all, the participants noted that personal experience add practical examples to theory during group sessions and help to better understand professional matters: /.../ when you listen to theory, there come examples from the group and you can graphically memorize them right away /.../ you know what they are talking about; to make important contacts: /.../ people whom I didn't choose become close to me; and to understand better what is happening to the group participants, how emotional experiences may distort facts: /.../ now I have a very clear vision how our experiences are sometimes distorted by feelings or sensations. The group members further note that the participation in experiential groups helped them to accept the otherness of other participants: /.../ the most important thing is to tolerate and admit that people are so different. There were behaviors that tended to irritate me and I couldn't accept it /.../ but now /.../ I accepted it as simply the diverseness of our existence. Likewise, relations with other participants became clearer due to increased openness and self-confidence: /.../ the problem with confidence, which was always in the background, /.../ broke through here /.../ and changed the inner feeling of self-presentation. This is very important, because higher level of self-confidence changed my co-existing in a relationship with others; and reduced feeling of personal strangeness: /.../ it was probably an important experience for me as a member in the female-dominant group. I was the only man. To tell the truth, this was scaring me all the time and stressful /.../ on the other hand, I felt closer to women, became more tolerant of them. In addition, the participants become less dependent on authority's opinions and attitudes: /.../ first listen to yourself and then compare it with what others say /.../ there is neither correct nor incorrect opinion; it's only an subjective opinion based on experience /.../ I should call it a sort of healthy way towards larger independence and professional maturity which is related to deidealization of certain authorities.

\section{Discussion}

The analysis of experiences of participants in the research revealed that the relationship between the participants and the experiential group, which is a multifaceted phenomenon, plays an important role for the perception of the experiential group in the training context.

The purpose of experiential groups in training which is emphasized in professional literature (Brabender, Smolar \& Fallon, 2004; Corey, 2004; Yalom \& Leszcz, 2005), i.e. giving meaning to theoretical knowledge and facilitation of personal changes, represents only one component of participants'relationship to the group. Besides it, this relationship also reflects preliminary expectations of participants that are linked both to individual needs of the participants and with their visions and theoretical knowledge about what they can expect from experiential groups.

One more component of the relationship between participants and the experiential group is the goals of the experiential group perceived by the participants. The analysis of participants' experiences demonstrates that the clearness and definiteness of the group goals are important for the participants. This aspect of experiential groups seems to be underemphasized both in theoretical and empirical research studies. Although Rose (2008) has mentioned that the clarity of goals of training and personal growth is the question frequently arising in experiential groups, this issue has not been given broader research. Yalom \& Leszcz (2005) states that considerations about what is more important - training or personal experience - reflect resistance of group members. However, such an explanation is not sufficient. The identification of preliminary expectations of experiential group members suggests members' own visions, what they might want from the group. However, once they encounter particular group experiences they get confused about what they should do and how to match learning with personal development in one and the same group.

The experience of inconsistence of goals of experiential groups in the training context is associated not only with the confusion about how to behave in the group and what questions to ask, but also with the role of group counselor which appears to be insufficiently clear to group participants and the lack of confidence in him as in a therapist due to emphasizing the counselor as a learning model. The goals of experiential groups seem to be an important theme in the work 
of the experiential groups and require more attention from both practitioners and researchers. It is also essential how the goals of experiential groups are identified by the group counselors, leaders and supervisors. Clarity and unambiguity of their position are important to the participants of experiential groups. These issues have been very little researched and revealed so far. Therefore, greater attention should be attached to the way the experiential groups are presented to trainees, how the goals of the experiential groups are identified and to what extent. Uncertainty of the goals of experiential groups also hinders the identification of personal goals in the group context.

It is quite probable that the uncertainty about the goals of experiential groups and the training context of the groups contribute to experiential groups being perceived as insufficiently safe and therapeutically weak, as well as raise doubts as to the naturalness of group processes. The experience of the participants at issue urges to pay attention to the similarities and differences of the members of experiential groups. The feeling of commonness in the group is vital and serves as a basis for the development of group cohesion (Yalom \& Leszcz, 2005). Too much variation among the group members makes it difficult to find common axes and cohere. Groups are perceived as weak and insufficiently safe. This experiential component of group members calls for attention to the selection of program participants. Selecting members to the program instead of group may result in excessive differences among group members and impede their integration into the group. Presuming that experiential groups are the basis of training group therapists, the issue of selection may turn to be of greater importance for success of the group than it was previously thought.

Another component important for group members in their relationship with the experiential group in the training context is the continuity of group processes which was noted by the group members. According to them, group processes are not only transposed form one experiential group into another, but also extent outside the group to lectures and supervisions. It means that an experiential group in training does not exist by itself: encounterings of group members outside experiential group have influence on the experiential group whereas encounterings within the experiential group influence behavior of program participants outside the group. And this should be taken into consideration by all program participants.

For further research studies of experiential groups, it is reasonable to focus more on the issues relating to the composition of experiential groups, selection of their members and identification and definition of the goals of experiential group that have emerged from the analysis of the experiences of the experiential group at issue.

\section{Conclusions and Implication}

The aim of the research presented in this paper is to explain how groups are perceived by group participants and to provide a structured description of the components of such experiences. In this paper the perception of experiential groups is revealed through a relationship between group members with the experiential group. The analysis of research findings revealed that the purpose of experiential groups in training which is attached the greatest attention in professional literature, i.e. giving meaning to the theoretical knowledge and facilitation of personal changes, represents only one component in the perceptions of this group. A relationship between group participants and the experiential group encompasses, inter alia, preliminary expectations of the participants, their concerns about the goals of the group, realization of weakness and unsafety of the group, as well as experience of group process continuity. The analysis of the research findings paid attention to the importance of identification and definition of the goals of experiential groups, because group members encountered the need to balance two crucial goals - learning and personal development that, according to the experiences of the participants at issue, are not so easy to reconcile. The blurred identification of the research objectives contribute to perceiving the group as weak and unsafe. This perception is even more reinforced by the vague understanding of the roles of experiential group counselor within the group (group counselors are perceived as learning models rather than therapists). Differences among group participants impede the construction of the feeling of commonness and encourage both researchers and practitioners to pay attention to the selection of participants to experiential groups and programs, especially where group therapy training through 
participation in experiential groups constitutes the basis of the program. Research participants also

paid attention to the group processes continuity: group processes are reflected in relations outside the group, whereas external relations are reflected in the experiential group.

The components of experiential groups in the training context identified in this paper may serve as research objects for further research studies of experiential groups and could considerably broaden the processes taking place in experiential groups in the training context, as well as organizational aspects related to experiential groups.

\section{References}

Anderson, R. D., \& Price, G. E. (2001). Experiential Groups in counselor education: Student attitudes and instructor participation. Counselor Education \& Supervision, 41 (2), 111-119.

Barker, C., Pistrang, N., \& Elliot, R. (Eds.) (2002). Research methods in clinical psychology: An introduction for students and practitioners. Second Edition. Chichester, England: John Willey \& Sons, LTD.

Boyatzis, R. E. (1998). Transforming qualitative information: Thematic analysis and code development. Thousand Oaks, CA: Sage Publications.

Brabender, V., Smolar, A.I., \& Fallon, A. E. (2004). Essentials of group therapy. Hoboken, NJ: John Wiley $\&$ Sons.

Braun, V., \& Clarke, V. (2006). Using thematic analysis in psychology. Qualitative Research in Psychology, $3(2), 77-101$.

Corey, G. (2004). The theory of group counseling. Sixth Edition. Pacific Grove, CA: Brooks/Cole.

Davenport, D. S. (2004). Ethical issues in the teaching of group counseling leadership training. The Journal for the Specialist in Group Work, 29 (1), 43-49.

DeLucia, J. L., Bowman, V. E., \& Bowman, R. L. (1989). The use of parallel process in supervision of group counseling to facilitate counselor and client growth. The Journal for Specialist in Group Work, 14 (4), $232-238$.

Gladding, S. T. (2008). Groups: A counseling specialty. Fifth Edition. New Jersey: Upper Saddle River.

Ieva, K. P., Ohrt, J. H., Swank, J. M., \& Young, T. (2009). The impact of experiential groups on master students' counselor and personal development: A qualitative investigation. The Journal for Specialist in Group Work, 34 (4), 351-368.

Jakubkaitè, B., \& Kočiūnas, R. A. (2013). Experiential groups in group counsellor training: A view through the multiplicity of contexts. Problems of Psychology in the 21st Century, 5, 12-22.

Johns, H. (2012). Personal development in counsellor training. Los Angeles, London, New Delhi, Singapore, Washington DC, Sage.

Kazlauskas, E. (Eds.) (2012). Psichologinių tyrimų etikos leidimų suteikimo tvarka [The assessment citeria for the issuance of psychological research permits]. Retrieved 15/03/2013 http://www.fsf.vu.lt/lt/ struktura/katedros/klinikines-ir-organizacines-psichologijos-katedra/mokslas\#psichologini\%C5\%B3tyrim $\% \mathrm{C} 5 \% \mathrm{~B} 3$-etika

Kline, W.B. (2003). Interactive group counseling and therapy. Upper Saddle River, NY: Merrill/Prentice Hall.

Lennie, C. (2007). The Role of Personal Development Groups in Counsellor Training: Understanding Factors Contributing to Self-awareness in the Personal Development Group. British Journal of Guidance and Counseling, 35 (1), 115-129.

Markus, H. E., \& King, D. A. (2003). A survey of group psychotherapy training during predoctoral psychology internship. Professional Psychology: Research and Practice, 34 (2), 203-209.

Merta, R. J., Wolfgang, L., \& MacNeil, K. (1993). Five models for using the experiential group in the preparation of group counselors. The Journal for Specialist in Group Work, 18 (4), 200-207.

Payne, H. (1999). Personal development groups in the training of counsellors and therapists: a review of the research. The European Journal of Psychotherapy, counselling \& Health, 2 (1), 55-68. 
46 Payne, H. (2001). Student experiences in a personal development group: The question of safety. The European Journal of Psychotherapy, counselling \& Health, 4 (2), 267-292.

Robson, M., \& Robson, J. (2008). Explorations of participants' experiences of a personal development group as a part of a counseling psychology training group: Is it safe in here? Counseling Psychology Quarterly, 21 (4), 371-382.

Rose, C. (2008). The Personal Development Group: The Students' Guide. London, KARNAC.

Shumaker, D., Ortiz, C., \& Brenninkmeyer, L. (2011). Revisiting experiential group training in counselor education: A survey of master's-level programs. The Journal for Specialist in Group Work, 36 (2), 111-128.

Stockton, R., Morran, D. K., \& Krieger, K. M. (2004). An overview of current research and best practices for training beginning group leaders. In J. L. DeLucia-Waack, D. A. Gerrity, C. R. Kalodner, \& M. T. Riva (Eds.), Handbook of Group Counselling and Psychotherapy (pp. 65-75). Thousand Oaks, CA: Sage Publication.

Yalom, I. D., \& Leszcz, M. (2005). The theory and practice of group psychotherapy. Fifth Edition. New York: Basic Books.

Advised by Ilona Čèsniene, Vilnius University, Lithuania

Received: January 30, 2014

Accepted: March 12, 2014

Biruté Jakubkaitė Master degree in clinical psychology, Postgraduate student (Doctoral studies) Vilnius University, Department of Clinical and Organizational Psychology, Universiteto g. 9/1 Vilnius, Lithuania.

E-mail: birutej@gmail.com 